Rafael Capurro - Raquel Capurro

\title{
Secreto, lenguaje y memoria en la sociedad de la información
}

\begin{abstract}
:
This dialogue between a psychoanalyst (Raquel Capurro) and a specialist in information ethics (Rafael Capurro) deals with the relationship between secrecy, language and memory in the information society. The first part addresses the present debate on privacy and the Internet from a psychoanalytic perspective (Freud, Lacan), taking into consideration the relationship between language and memory. The second part deals with the concept of secrecy with regard to oblivion and censorship in the context of the digital network as a space in which seemingly anyone can tell anything to everybody. The question of "what cannot be said" is posed from a psychoanalytic perspective. The third part explores the relationship between memory and secrecy. Secrecy is defined as a "dispositif of exclusion." The concept of "information society" is contrasted to a "society of secrecy". This strategy opens a debate about the question of secrecy in the information society that might also help to disambiguate this concept when applied to concrete situations and spheres in which the question of where to draw the line arises.
\end{abstract}

\section{Agenda:}

1 Introducción

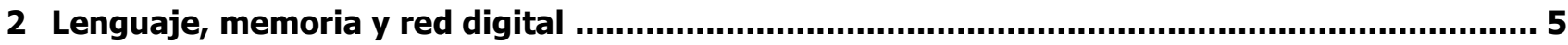

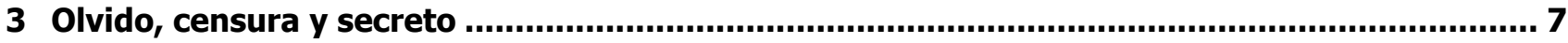

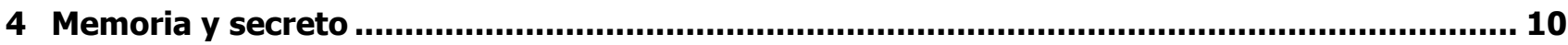

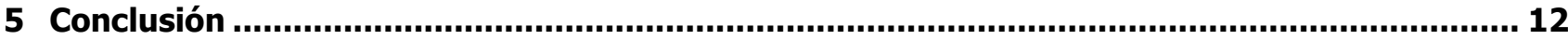

\section{Authors:}

Prof. (em.) Dr. Rafael Capurro:

- Redtenbacherstrasse 9, 76133 Karlsruhe, Germany

- 留 + 49 - 721 - $9822922, \square$ rafael@capurro.de, ㅁww.capurro.de

- Relevant publications:

- Rafael Capurro - John Holgate (eds.). Messages and Messengers. Angeletics as an Approach to the Phenomenology of Communication. Munich: Fink 2011.

- Intercultural Information Ethics. In: Kenneth Einar Himma and Herman T. Tavani (eds.): The Handbook of Information and Computer Ethics. New Jersey: Wiley 2008, p. 639-665.

Psyc. Raquel Capurro:

- Benito Blanco 747, Ap. 701, 11300 Montevideo, Uruguay.

- $\mathbb{2}$ ? $+598-2$ - 7106129, $ه$ recap@internet.com.uy

- Relevant publications:

- Comte. Actualidad de una herencia. Mexico: Epeele 1999. (Trad. al francés: Le positivisme est un culte des morts. Paris: Epel 2001).

- El sexo y su sombra. Del misterioso hermafrodita de Michel Foucault, México: Epeele 2004. 


\section{Introducción}

Rafael Creo que existe hoy un "malestar en la cultura"1, con relación a la comunicación digital. Se percibe tanto una euforia en Internet con relación a la posibilidad de decir todo a todos, sin límites de espacio y tiempo pero sobre todo de contenido. También se da una inseguridad provocada a nivel del e-mail diario por el SPAM y los virus debido a la influencia cada día mayor de la red digital en todos los aspectos de la vida social.

Vivimos en una sociedad de mensajes digitales en la que parece haberse realizado aquel sueño de la Ilustración de eliminar todo tipo de barreras o de censura impuestas por el poder político y su aliados, el poder militar, religioso y moral. ¿Quién puede enviar mensajes? ¿de qué tipo? ¿a quién? ¿en qué medio? ¿con qué alcance espacio-temporal? ¿con qué posibilidad de que puedan ser o no distorsionadas? ¿con qué formas de ser conservadas? Y, sobre todo, ¿cómo sustraerlas al alcance de quienes no debieran conocerlas sin previo consentimiento de los sujetos que los producen y sustentan? ¿Y todo esto en base a qué regla o programa y con qué repercusiones a nivel individual y social? En una palabra: ¿cuál es el lugar del secreto, en un sentido amplio de este concepto, en la sociedad de la información digital?

Es una situación paradójica si la contrastamos con el siglo XIX y comienzos del siglo XX, es decir con la época de Freud como la describe, por ejemplo, en el capítulo 3 de su ensayo sobre el "malestar en la cultura" publicado en $1930^{2}$. Paradójicamente la ciencia y la técnica, el meollo de la cultura, que consideró como "sublimación" ("Sublimierung") de los instintos se ha vuelto un problema. ¿Cómo ves tú estos conflictos y en especial cómo ves tú el fenómeno de la delimitación entre lo público y lo secreto así como entre lo público y lo privado? Naturalmente que el tema del secreto va mas allá de la discusión sobre la privacidad tan virulenta hoy en día. El secreto está conectado al fenómeno de la memoria, individual y colectiva: sólo podemos guardar un secreto si de alguna manera lo fijamos en la memoria para lo cual necesitamos el lenguaje, y, en la sociedad de la información actual, a la memoria digital.

Raquel. Empezar un diálogo sobre ese tema, me parece interesante. El asunto tiene muchas puntas, por ejemplo, como tú señalas, el de la formulación de diferencias entre lo público y lo privado. Las diferencias hoy aparecen multiplicadas y quizá sea más acertado hablar de los públicos adecuados a cada tipo de comunicación. Si consideramos además la dimensión política de estos temas relativos a la información y al secreto, hemos vivido en los últimos años, en Uruguay, las tensiones sociales derivadas de políticas en donde los archivos secretos de las dictaduras militares, el secreto "militar", han jugado claramente como factor de poder. Siguiendo a Michel Foucault, no creo que lo que puede saberse y decirse en una sociedad, esté por fuera de esa lucha de poderes que constituyen a la vida social. Los secretos industriales ponen en evidencia el capital que representan ciertos conocimientos en las luchas competitivas por el mercado. Ya sea como secreto o como censura, el circuito de las palabras ve marcados sus límites epocales.

Pero quiero llevar mi intervención a un campo más restringido, el campo del psicoanálisis, en donde se pone en juego un dispositivo que pareciera otorgar todas las libertades al decir y al recordar de un individuo. Espacio de privacidad en donde se hará público ante el analista y para quien habla aquello que allí será dicho. ¿Qué sucede cuando la única regla de juego es decirle al analizante "Diga sus ocurrencias"? ¿Qué sucede en esa experiencia? Freud fue sorprendido por la conexión que se establecía entre ciertos recuerdos que afloraban y los síntomas que aquejaban a sus pacientes. Esta cuestión no tiene hoy indudablemente el mismo marco de referencia que tuvo Freud. Se hace patente, creo, en tu misma intervención de apertura de este diálogo. Estamos lejos de las teorizaciones de Freud. Sí, pero también estamos lejos de prácticas del lenguaje que, como el psicoanálisis, solo pueden sostenerse en otra concepción de la relación entre el

\footnotetext{
${ }^{1}$ Freud 1974.

${ }^{2}$ Freud op.cit.
} 
sujeto y la lengua que habita y lo habita. No veo como abordar los problemas de la memoria y del secreto en el psicoanálisis sin señalar este punto de partida. La regla analítica de la asociación libre puede guiar una cura en la medida en que el yo acepta soltar sus riendas y deja vagabundear sus pensamientos. En medio de esa situación emergen recuerdos evocados con ciertas palabras, y no otras, con el sabor, el timbre y el saber de la lengua particular del hablante que allí está. Esos recuerdos, que Freud llamó encubridores, permiten tramitar los entramados libidinales que viajan en las palabras, en sus silencios, en los síntomas que, con su críptico cifrado, señalan vivamente el fracaso de las fuerzas opuestas a la traducción en palabras de las vivencias subjetivas. Freud llamó a esta fuerza operativa y silenciadora, "Verdrängung" y creyó hasta 1914 que bastaba el dispositivo de la asociación libre para que finalmente la rememoración de lo traumático aflorara en el decir. Y bien, no. "Wiederholung": aquello que no se recuerda retorna, pero no como recuerdo, sino en los actos que transferencialmente ligan analizante y analista. De ahí un atolladero freudiano. ¿Cómo tratarlo?

En el plano social esta pregunta se instaló de otra manera durante el correr del siglo XX. El espanto de los genocidios cometidos, de los actos de barbarie, que afrentaron y afrentan la convivencia, se levantó la consigna de la memoria contra la repetición. Los pueblos que no recuerdan su historia están condenados a repetirla, se ha dicho, y hasta cierto punto podemos acordarlo. Pero... cacaso la memoria tiene operatividad respecto a la repetición? Esto requiere un ensanchamiento de la problemática de abordaje. En la década del 50 varias disciplinas, entre ellas el psicoanálisis, pudieron plantearse la relación del sujeto al lenguaje en el nuevo marco de la lingüística saussuriana. Fue un primer tiempo en el que Jacques Lacan buscó respuesta a esa pregunta freudiana releyendo La Carta robada de Edgar A. Poe. ¿La repetición es acaso la simple reproducción de una conducta regida por el retorno de un significante reprimido? Fue la primera posición de Lacan que leemos por ejemplo en 1955: "Nuestra investigación nos ha llevado al punto de reconocer que el automatismo de repetición ("Wiederholungszwang") toma su principio de lo que hemos llamado la insistencia de la cadena significante". ${ }^{3}$

Sin embargo, los agregados que Lacan fue haciendo a ese texto permiten leer un cambio en su posición. Como lo señala unos años después, lo que está en juego aquí, a lo que hay que dar respuesta "es a la estructura misma de la determinación" del hablante. ${ }^{4}$ Lacan se deja guiar por el ternario que ya propuso en 1953 y que rige su producción teórica: el hablante existe en el imaginario, simbólico y real, registros de sus experiencias, registros - dirá en la década del 70 - que se anudan en cadenas borromeas.

\section{Lenguaje, memoria y red digital}

Rafael Si me permites hacer de nuevo el pasaje de lo individual a lo social: un efecto del psicoanálisis freudiano podría concebirse como el deseo de "otorgar todas las libertades al decir y al recordar", como tú dices, en base a un nuevo medio.

Los orígenes de la red digital que llamamos internet se encuentran en una necesidad social de comunicar todo a todos como la piensan los filósofos de la ilustración con su crítica a la censura concibiendo la utopía de una sociedad con una memoria abierta y accesible a todos, en la cual todos puedan decir todo y recordar todo. Esto se traduce luego, por ejemplo, en las libertades de la generación de 1968 como reacción a la contrautopía del fascismo donde nadie podía decir nada a nadie sin tener en cuenta que eso era un peligro mortal. El fascismo concibe la 'sociedad del secreto' desde arriba, con una jerarquía de poder basada en archivos y mensajes administrados por una policía secreta, la Gestapo (abreviación de "Geheime Staatspolizei" o policía secreta del estado). Pero también los fascismos de izquierda, el stalinismo por ejemplo, basan su poder en este esquema y liquidan a millones.

\footnotetext{
${ }^{3}$ Lacan 1966, p. 11.

${ }^{4}$ Ibid. p. 52
} 
No es entonces por casualidad que una máquina que obedece órdenes ciegamente como es la computadora, se transforme paradójicamente en un medio social en el cual se proyecta un ideal de información generalizada, una 'sociedad de la información' como contra-dicción a una 'sociedad del secreto'. Visto así, secreto e información son conceptos opuestos. Pero esta oposición es relativa, ya que hay informaciones en la sociedad de la información digital que quedan restringidas a un grupo. Todo secreto tiene una dimensión social. Nadie puede tener algo secreto concebido desde y para sí mismo.

Hablar de secreto e información es por tanto, como tú lo indicas, hablar de y desde el lenguaje como el horizonte en el que forman y transforman los diversos modelos individuales y sociales de memoria e información. Aquí entra el sustento de los significantes como preludio a lo que en la técnica de la red digital es el sustento de un traductor que permite que las distintas computadoras puedan intercambiar mensajes a pesar de hablar lenguajes diferentes.

Lo que acontece cuando estamos en la red de los cuerpos digitales que llamamos internet es, por un lado, un proceso 'maquinal' o subsemántico entrecruzado con el lenguaje humano. Desde el punto de vista semántico, la red digital es una máquina gigantesca de repetición donde todo está en espera que alguien piense que lo que está ahí expuesto sea visto como algo relevante es decir como un mensaje en espera de un asentimiento. El sujeto que es así tocado por la información queda sujetado a ella cuando esta se vuelve mensaje y el usuario se vuelve su cómplice.

Por cierto que en este complejo sistema de traducciones todo queda abierto a 'traiciones' puesto que lo que es expresado en un lenguaje sólo puede ser referido en el otro con un código diverso. Pero siendo así como ambos sistemas son sistemas del sujeto, hay siempre algo que les es común. Lo que le duele al sujeto y es censurado queda enganchando en diversos códigos, con distintos sistemas de secreto y memoria. En el plano social los sistemas criptográficos son un intento ensamblador de traducir significados informacionales en significantes secretos. Visto así podríamos definir el fenómeno del secreto como el pasaje de un significado expresado en un lenguaje a un lenguaje de otro género utilizando para ello un traductor. La red digital ofrece por un lado la posibilidad de poner a disposición de forma infinita todos los significados posibles, pero lo hace sirviéndose de un significante que es parte de otro género, la computadora. Esto hace posible desde el inicio mismo de la sociedad de la información la creación de una memoria accesible solamente a quienes puedan comprender su lenguaje secreto. Creo que esto no es propio de la sociedad de la información actual, sino que caracteriza a toda sociedad humana en tanto en cuanto su habla es desde su propio origen biológico un lenguaje mixto, al que los hablantes están sujetos en el momento mismo en que se conciben como sujetos hablantes y capaces de informar pero también de guardar un secreto.

Raquel Has llevado el tema a aspectos muy interesantes que me plantean el problema de si no le estarías dando una compatibilidad demasiado extensa a lo que sucede en distintos registros que tu llamas "de lenguaje". Esto nos lleva a prestar particular atención a este su modo de jugar con la polifonía de los sonidos con los que cifra el real y lo convierte, al decirlo, en acontecimiento y/o recuerdo, pero también en fijación virtualmente móvil. Cuando la fijación queda rígida, y constituye un signo, como aquellos cifrados en mensajes codificados, de máquinas, (como en el semáforo) o de animales (condicionamientos conductuales) y/o de estructuras celulares o genéticas estamos en un sector de preguntas que son diferentes a las que se plantean si no olvidamos la poética del lenguaje. Esta aparece a veces como irrupción loca cuando alguien por ejemplo, le atribuye sentidos incompartibles a los cambios de luces de un semáforo. Ya sea con fines científicos, bélicos - o, a nivel individual, sintomáticos - estamos ante una situación peculiar que plantea su descifrado y su integración o no, al fluir polivalente del decir. Por eso me parece que el concepto mismo de traducción ha de ser considerado más de cerca ya que tal como tu lo usas implica operaciones diversas: de cifrado, de descifrado, pasaje de sistemas de escritura a otros, transcripciones de sonido y por último, pasajes de sentido de una lengua a otra, a lo que propriamente se ha llamado traducción. La rememoración juega con todas estas posibilidades, como lo da a leer la obra de Proust, por ejemplo. Las fallas en el sistema neuronal traen consecuencias para el hablante, pero hay allí una discontinuidad a señalar, así como hay una discontinuidad, un hiato entre lo que ocurre y las versiones que se fabrican sobre ello. Lacan, en 1964, señalaba que no toda la vida pulsional nos es asequible a nosotros 
mismos, sólo aquello que de la sexualidad pasa "por los desfiladeros del significante". En esa línea la experiencia analítica indica que "todo" no puede decirse y que ese límite es distinto al de la censura o el secreto, pues es un límite de nuestra con-formación misma. Por eso concuerdo en que "una necesidad social de comunicar todo a todos" como la piensan los filósofos de la ilustración con su crítica a la censura sitúa la utopía de una sociedad con una memoria abierta y accesible a todos, en la cual todos puedan decir todo y recordar todo.

De modo más amplio en este nivel se plantea el problema mismo del historiador así como el del testigo. En estos días me encontré con la creación en Uruguay de un "museo de la memoria" que, como sucede con muchos otros creados en el mundo, busca preservar del olvido acontecimientos que han sido traumáticos para una generación. ¿Cómo se sitúa la nueva generación ante aquello que recibe a modo de legado? Toda una cuestión.

\section{Olvido, censura y secreto}

Rafael Con respecto a lo que indicas al final sobre el "decir verdadero" como lo plantea Michel Foucault en su curso sobre la parrhesía ${ }^{5}$, creo que es importante ver este tema tomando como contraste la tradición oriental, y en especial la de la China clásica, del "decir indirecto" como lo investiga François Julien haciendo especial referencia al sabio taoista Dshuang Dsi (365-290 AC). ${ }^{6}$ En otra ocasión he tratado de mostrar la relevancia de esta contraposición entre "decir directo" y "decir indirecto" para la configuración de distintos tipos de sociedades de la información. ${ }^{7}$ Lo que dice Lacan sobre la relación entre la mano y el agua del río expresa la relación taoista con la naturaleza como un proceso ("dao") en el que estamos inmersos y que "alimenta la vida" como dice Jullien. ${ }^{8}$

Como tú dices, es importante hacer una diferencia entre lo que no se puede decir y permanece secreto pero que va pasando por los diversos significantes o en la manera del "decir indirecto" y el concepto de secreto asociado a la censura. Además está también el concepto de privacidad tanto en el sentido de poder disponer libremente de lo que quiero decir a otros como el de impedir a que otros entren en el espacio privado. Cuando los filósofos de la ilustración hablan de libertad de censura y en el siglo XIX de libertad de prensa se refieren, como tú dices, al concepto de secreto como algo impuesto por un poder que me obliga a no poder comunicar algo que querría que otros supieran. La necesidad social de poder comunicar todo a todos surge como utopía informacional en este contexto. Pero al mismo tiempo hay límites de este deseo social que se manifiestan por ejemplo en la necesidad de mantener secretos diversos tipos de conocimientos como los llamados secretos de estado o también los secretos de una empresa que protege su saber frente a la posibilidad de que sus productos sean copiados por los competidores.

En estos y otros casos ubicamos el concepto de secreto en el ámbito de poder el cual también pone límites (variables) a la utopía del poder comunicar todo a todos. Creo que estos límites no son sólo un problema de censura sino también que están dados por el carácter esencialmente limitado de la comunicación humana. Por otro lado el desarrollo actual de la red muestra la inmensa atracción de esa máxima ética: 'iComunica todo a todos!' que se transforma en un imperativo moral y conduce al desarrollo de los movimientos sociales en la red discutidos hoy bajo el término de Web 2.0. Dichos movimientos que comenzaron con listas de mensajes y chats se transforman ahora en grupos de todo tipo en el que los integrantes se reúnen en torno a un interés común, intercambiando todo tipo de mensajes multimediales en torno a un blog, construyendo un wiki, o intercambiando videos en YouTube. Esto se expresa también en el campo de movimientos

\footnotetext{
${ }^{5}$ Foucault 1983.

${ }^{6}$ Jullien 1995.

${ }^{7}$ Capurro 2006.

8 Jullien 2005.
} 
políticos de todo tipo y color asi como grupos al margen o en contra de la legalidad como son por ejemplo los de pornografía infantil.

Creo que tendríamos que profundizar la relación entre secreto y memoria tomando como hilo conductor los tres sentidos de secreto que vamos elaborando, es decir:

1) secreto como dimensión de lo decible sólo indirectamente,

2) secreto como lo reprimido por procesos de censura y

3) secreto como lo que pertenece al campo privado.

Esta diferenciación tiene tal vez la desventaja de ensanchar demasiado el contenido intencional del concepto de secreto, sobre todo en el caso de la tercera definición que tiene relación con lo íntimo y confidencial.

El conservar un secreto ("Geheimhaltung") es, como lo indica Hemma Boneberg, ${ }^{9}$ una estrategia de la evolución en el sentido de una máscara o un camuflaje que impide que los competidores en el campo de la alimentación o la reproducción puedan sacar provecho del otro. En el humano se produce un proceso de segundo grado para conservar un secreto en base a signos que representan lo ausente en lo presente, haciéndolo al mismo tiempo patente. En otras palabras un signo secreto patente está codificado en forma doble.

Estamos en el campo del saber y del querer callarse en determinadas situaciones. Lo cual nos lleva una vez más a las pregunta de ¿quién dice o no qué cosa a quién, en qué situación, con qué razones etc.? Podríamos discutir la tesis que secreto y memoria, vistos en esta perspectiva amplia semántica e histórica, son algo específicamente humano en tanto que en ellos se juega un proceso de velamiento y develamiento de segundo grado, es decir codificado y reflexionado linguísticamente. Para el filósofo Georg Simmel la forma negativa específica de desocultamiento de un secreto es la traición ("Verrat"). ${ }^{10}$

Raquel Retomo algunas de tus incursiones: "es importante - dices - hacer una diferencia entre lo que no se puede decir y permanece secreto pero que va pasando por los diversos significantes o en la manera del "decir indirecto" y el concepto de secreto asociado a la censura". Sí, acuerdo contigo y agrego una complejidad más: lo que permanece secreto es algo que se supone inscripto en algún sistema de escritura o codificación. Esto es a diferencia de aquello que se experimenta y no tiene inscripción. Hay experiencias centrales que no pueden decirse, y no por ser secretas ni por estar reprimidas, sino porque no hay manera de inscribirlas: supongo que a ello alude Wittgenstein al final del "Tractatus". ${ }^{11}$ Quedar mudos ante la muerte no es quedar con un secreto, ni ante algo reprimido sino ante la imposibilidad de decir. Todo lo que allí se diga no anulará ese vacío, el decir indirecto le hará borde $\dot{c}$ ? pero no creo que pueda llamarse a eso que no se puede decir un secreto, salvo en forma metafórica. Creo que estamos, como decía Wittgenstein, dándonos de cabeza contra los muros del lenguaje. Esto da el marco del decir. Su límite.

Rescato contigo el valor del decir indirecto y recordé a propósito el libro de Leo Strauss sobre "La persecución y el arte de escribir", en el que analiza los procedimientos alusivos de Maimónides para hacerse entender por quienes quería hacerse entender y quedar opaco para los demás. ${ }^{12}$ Quienes hemos vivido

\footnotetext{
${ }^{9}$ Boneberg 1999.

${ }^{10}$ Simmel 1995, p. 409.

${ }^{11}$ Wittgenstein 1984.

${ }^{12}$ Strauss 1989.
} 
situaciones de persecución política sabemos que la alusión se vuelve en esas circunstancias un refinado método de astucias para hacer llegar un mensaje a ciertos destinatarios y no a otros.

El darle la palabra a un analizante, supone darle un lugar a una verdad que está ahí, sin que sepamos qué dice como algo "casi-inolvidable" ${ }^{13}$ para que al fin pueda descansar en paz. El mensaje críptico a leer en sueños y síntomas no debiera instalarse como un imperativo de recordar ni de abolir el secreto, lo que sólo serían nuevas imposiciones superyoicas: "Hay que decirlo todo, recordarlo y confesarlo todo". Si así ubica el analista la regla de juego, bien merece las críticas de Foucault cuando observa la puesta en funcionamiento en el siglo XIX del dispositivo de la sexualidad como dispositivo de confesión y cuando considera que el psicoanálisis sería su última producción. Pero si como psicoanalista hago mía la crítica foucaultiana, diré que se trata en la experiencia del análisis de esos juegos de verdad que el mismo Foucault señala y en parte toma de Wittgenstein. Esos juegos en el análisis tienen reglas, que no son de revelar lo secreto ni de ser sinceros, sino de decir las ocurrencias del momento. Ese juego, señala Jean Allouch, ${ }^{14}$ abre también la puerta al engaño, a la imaginación, a los recuerdos, etc.

Creo que recortamos así una pregunta acerca del estatuto del secreto, ya sea individual, familiar, político, militar, industrial, etc. Hay archivos secretos. Aquellos a los que no se llega fácil. ${ }^{15}$ También los archivos se depositan allí donde la memoria falla. Estos no exigen el secreto. Lo secreto es activamente puesto aparte por alguien. Es un dispositivo de exclusión. Cuando alguien habla y se le hace presente un secreto que no quiere decir, lo que ocurre a menudo es que enmudece, pues todo su flujo asociativo queda enlazado a ese secreto. Por eso en un análisis el secreto trampea la regla de juego. "Diga lo que se le ocurra".

Ahora y con estos rodeos llego a tu propuesta: "Creo que tendríamos que profundizar la relación entre secreto y memoria tomando como hilo conductor los tres sentidos de secreto que vamos elaborando, es decir:

1) secreto como dimensión de lo decible sólo indirectamente,

2) secreto como lo reprimido por procesos de censura y

3) secreto como lo que pertenece al campo privado."

Esta diferenciación tiene tal vez la desventaja de ensanchar demasiado el contenido intencional del concepto de secreto, sobre todo en el caso de la tercera definición que tiene relación con lo íntimo y confidencial. Y llego a la conclusión que está 1 . el decir indirecto; 2 . el retorno de lo reprimido 3 . y el secreto que se instaura en la esfera pública o privada. Como verás me inclino a no seguirte en esa ampliación del concepto de secreto. Quisiera detenerme por último en la censura tal como se instaura en la esfera pública, por ejemplo, la censura de lo que se escribe. La censura aparece como un movimiento de tachadura que deja ver aunque más no sea por los blancos que instaura en los periódicos como señalaba Freud, una operación en la que algo es puesto afuera. Freud no identifica censura y represión.

Respecto al meollo del asunto quiero enfatizar desde el punto de vista en que estoy colocada

1. la riqueza y complejidad de las relaciones del hablante con la lengua que lo habita y el riesgo de reducir esa complejidad.

\footnotetext{
${ }^{13}$ Allouch 1998.

${ }^{14}$ Allouch, op.cit.

${ }^{15}$ Derrida 1995.
} 
2. Una forma de incurrir en ese riesgo sería alimentar la utopía de que todo puede decirse en la red, y en los encuentros virtuales. Rescatar pues el decir de los cuerpos vivos y presentes que disponen también de esta vía para entrar en comunicación.

3. Respecto a la relación memoria secreto: creo que acentuaría su estrecha conexión con los poderes en juego, cada vez que se traman con los saberes de la época. Los historiadores están concernidos en forma particular por esta cuestión de lo que se selecciona y se silencia al hacer historia, así como cada persona cuando historiza tramos de su vida. Pero lo que se silencia no necesariamente se convierte en secreto.

\section{Memoria y secreto}

Rafael Concuerdo contigo en que es más correcto definir al término secreto como algo que se instaura en la interfaz de lo que en una sociedad se considera como privado y público, siendo estas categorías de segundo orden, es decir que no son propiedades de algo (un texto, una foto, un evento de cualquier tipo) sino algo que se les atribuye en un juego social. La diferencia entre lo privado y lo secreto hace relación, en el caso del secreto, a algo que se quiere activamente impedir que otros tengan noticia. En un sentido todavía más estricto podríamos añadir que la razón de mantener algo secreto es que su conocimiento por terceras partes puede ser de daño (directa o indirectamente) para quien lo custodia. Además podríamos distinguir tipos de secretos de acuerdo a su contenido y el estatuto o situación de la persona o el grupo que lo custodia, como ser por ejemplo el secreto de estado. Finalmente habría que analizar no sólo la relación entre secreto y lenguaje sino también la atribución de la característica de secreto a todo tipo de objetos y de relaciones entre los mismos. Todo un cosmos que ensancha lo que se suele llamar criptología, un término que relaciona lo oculto (kryptós) con el lenguaje (lógos) y alude a las técnicas para ocultarlo.

Te propongo hacer una distinción conceptual entre 'sociedad de la información' y 'sociedad del secreto'. Llamo 'sociedad de la información' a aquella que está estructurada con una tendencia horizontal o democrática, mientras que la 'sociedad del secreto' tiende a esquemas jerárquicos o verticales, como es el caso de sociedades fascistas del siglo pasado, la del Ancien Régime francés así como las sociedades medievales y las de la antigüedad con excepción (relativa) de la democracia griega y sus sucesoras, en especial las democracias modernas. En las sociedades del secreto tiende a eliminarse el dominio privado o este vale sólo para una persona, un partido, una casta... que guarda secreto su saber para el resto de la sociedad, no permitiendo que nadie tenga acceso a su poder.

Las sociedades democráticas se caracterizan por tener un dispositivo para descubrir algo (supuestamente) ilegal que alguien intenta ocultar - este es el sentido de la libertad de prensa como un cuarto poder político - y otro dispositivo, el de la protección de datos personales, que impide que el estado o grupos sociales, se sirven de informaciones ilegalmente o sin el consentimiento adecuado. A fines del siglo XX la libertad de prensa tiende a abusar de su poder no sólo como instrumento político sino también sobrepasando los límites de la privacidad en busca de escándalos que le procuren un mayor rendimiento económico. El estado, a su vez, se sirve cada vez más de la red digital mundial y de todo tipo de instrumentos de observación y control, para, en los mejores casos, aumentar la seguridad social al costo de las libertades individuales. Esta tendencia se acelera sobre todo después de los acontecimientos del 11 de setiembre de 2001 en Estados Unidos y la consecuente lucha contra el terrorismo. Pasamos entonces de la democracia basada en la libertad de prensa y la abolición de la censura, sobre todo en relación a los libros y demás productos de la era de Gutenberg, por la mediocracia del siglo XX hasta llegar a la 'netocracia' (netocracy), o poder de la red, de fines del siglo pasado y comienzos del siglo XXI. Lo curioso es que la pérdida del sentido de lo privado no sólo no es vista a menudo como algo negativo, sino que gran número de personas ponen libremente en la red aquello que antes se consideraba como privado y en muchos casos, sobre todo en el plano sexual, como secreto o íntimo. El exhibicionismo pasa a ser un valor social y la red digital se transforma cada vez más un medio de exhibicionismo. 
Pienso que toda sociedad humana funciona con el código desvelar/ocultar ${ }^{16}$ y que dicho código es un "concepto de la reflexión" ("Reflexionsbegriff") como los llama Kant, en contraposición a conceptos que expresan cualidades de objetos La base sobre la que descansa este código desvelar/ocultar es la memoria, tanto individual como colectiva. La cual a su vez se sirve del dispositivo del olvido y del recuerdo para frenar y reprimir o para acelerar, como catalizador, los cambios sociales y en especial las reglas morales vigentes. Vista así, la ética, como la concibe Michel Foucault en sus clases sobre la parrhesía citadas anteriormente, es un dispositivo catalizador o un síntoma del desacuerdo entre una interpretación fija, en el sentido de "cualidad de objeto", de lo que se ve como moralmente permitido de ser ocultado o descubierto. En muchos casos se produce un efecto social "amfibólico" (en sentido Kantiano) del cual se sirven abundamente los medios de masas en tanto que actúan como altoparlantes de la moral vigente o de lo que se considera como 'políticamente correcto'.

Los blogs y los wikis así como todo tipos de foros digitales y redes sociales de intercambio, como Facebook y Twitter, en todos los campos imaginables y abarcando tanto a grandes comunidades de millones de participantes hasta grupos selectos son índices de un cambio de las categorías de secreto y desvelamiento que cuestionan muchas delimitaciones y reglas morales y legales vigentes en comunidades, culturas y estructuras políticas así como complejos mediáticos de difusión vertical de mensajes, cuyas consecuencias positivas y negativas a distintos niveles recién empezamos a percibir y a pensar.

Raquel Casi me quedaría callada después de tu excelente desarrollo pero en el mail que me dirigías acompañando este texto pasó algo que me parece importante hacer público. Me escribes que leíste en el último número del Magazine littéraire ${ }^{17}$ dedicado a "les ecritures du moi, autobiographie, journal intime, autofiction" una expresión paradójica "journal extime". Esa expresión operó como una llave, una clave olvidada. ¿Cómo no había recordado ese término central que inventa Lacan para designar el estatuto particular que cobra a veces el decir o el hacer público?

Voy a situar ese término para luego responder a esa pregunta. En su seminario sobre "La ética del psicoanálisis" ${ }^{\prime 18}$ Lacan se encuentra hablando del arte, en particular de las anamorfosis, y alude a las pinturas rupestres de las cuevas de Altamira: esa cueva en donde sorprendentes imágenes fueron dejadas allí como pruebas objetivas del ejercicio artístico en un pasado remoto, pero pruebas subjetivas también pues a través del tiempo nosotros, al contemplarlas, somos puestos a prueba en ese encuentro. Ellas nos remiten al ejercicio de creación que se organiza en torno a un vacío, delimitado, el de una pared, el de una página en blanco, el de una pantalla. Ese lugar vacío, 'presentificado' por la caverna (de Altamira, de Platón, de nuestras pantallas) opera, según Lacan como lugar central desde donde opera la creación a la que califica como "esa exterioridad íntima, extimidad, que es la Cosa"19 en cuya cercanía algo se produce.

La Cosa, con acentos kantianos, remite a Freud cuando en sus primeros escritos, que Lacan trabajaba en ese año, describe, en las experiencias iniciales del encuentro con el prójimo, la presencia de dos componentes, aquel que se ofrece al discernimiento y el que permanece como Cosa que escapa al sujeto, "das Ding", dice Freud. En 1969, Lacan retoma el término, "éxtimo" y precisa, "lo que nos está más próximo, siéndonos a la vez exterior" ("ce qui nous est le plus prochain tout en nous étant extérieur". ${ }^{20} \mathrm{El}$ espacio de la exterioridad-interioridad que la caverna abriga, la extimidad, muestra que la topología para pensar la relación del sujeto con el campo del Otro no puede recurrir ya a la simplificación de un adentro y un afuera. De ahí todas las búsquedas en esta dirección efectuadas por Lacan a partir de esos años.

\footnotetext{
${ }^{16}$ Simmel, op.cit., p. 405-406.

${ }^{17}$ Geffroy 2007.

${ }^{18}$ Lacan 1960

${ }^{19}$ Lacan 1960.

${ }^{20}$ Lacan 2006.
} 
Retornando al e-mail que me enviaste: al leerlo en mi pantalla una palabra resonó y despertó lo mío que necesitaba ese recorrido éxtimo para reaparecer. Reconocerlo, en este caso era fácil, no siempre lo es, y hacer con ello algo nuevo. Este pasaje por el campo del Otro permite encontrar lo que ya no merece ser llamado "propio", pero que permite al sujeto subjetivarse allí.

\section{Conclusión}

Rafael Un hermoso ejemplo de memoria a través del otro y también a través de la pantalla digital y global que llamamos internet. La red digital mundial es algo así como un modo óntico del "ser-en-el-mundo" (M. Heidegger) en un medio que nos abarca pero sin ser una transcendencia metafísica.

El subjetivarse en y a través de la red en las diversas formas posibilitadas por los nuevos dispositivos de la Web 2.0 y su intersección con los móviles celulares así como con todo tipo de comunicación digital que enreda al cuerpo humano individual con su entorno social, político y ecológico, implica entrar en este juego de memoria y olvido digital con todas las ambigüedades, promesas, desilusiones, y peligros totalitarios que este medio hace posible siendo muchas veces difícil trazar la línea divisoria entre un estado democrático que intenta proteger a sus ciudadanos reduciendo su privacidad y opacidad en base a técnicas digitales de observación y control que pueden desembocar casi sin percibirlo en una sociedad de control.

Visto así, el tema del secreto entendido como algo que el sujeto no desea que llegue a ser de conocimiento público, se vuelve paradójicamente un asunto de capital importancia para una sociedad democrática. El derecho a la privacidad se puede entender entonces no sólo como el derecho a impedir que el estado entre en el recinto del sujeto, sino también en el sentido de que el sujeto tiene derecho a decidir cuál información que le incumbe, a distintos niveles y en relación a distintas prácticas, va a ser abierta al público con su consentimiento. En Alemania existe este derecho bajo el término de la "autodeterminación informacional" ("informationelle Selbstbestimmung").

Recordemos también que es justamente la red digital mundial la que provoca la crisis de aquellos regímenes modernos como son las patentes y el derecho de autor que fueron creados justamente para evitar los conocimientos secretos, proporcionando la protección legal a los inventores, autores y creadores artisticos. Tanto la ciencia como la economía modernas no pueden avanzar si no se comunican públicamente los conocimientos. Pero, al mismo tiempo, dicha comunicación no es ni absoluta ni está desprovista de dispositivos de seguridad con los cuales se crean diversas formas de privacidad y límites de acceso. Ninguna empresa, como tampoco el estado, pueden prescindir de plantearse la pregunta por el límite entre lo público y lo privado incluyendo lo estrictamente confidencial o secreto. Son innumerables los casos en los que se pueden observar la ambigüedad de dichas delimitaciones como, por ejemplo, el no publicar resultados negativos en el caso de una investigación científica cuyo conocimiento pueda llevar a cuestionar un proyecto o un producto, como tú lo indicabas ya al comienzo de este diálogo, así como también las innumerables formas de re-escribir el pasado de un país o de una empresa o de una persona... de tal manera que sólo se recuerde aquello que es conveniente a quienes detentan el poder.

Podemos decir entonces que la dimensión de lo secreto como límite de algo segregado, es inseparable de lo abierto o público de tal modo que el código secreto/público que se entrecruza con el de memoria/olvido es algo que caracteriza a toda sociedad humana en cuanto esta se constituye en el lenguaje. En este diálogo hemos intentado mostrar, de forma muy sintética y a menudo tangencial, cómo dichos códigos se juegan, entrecruzándose a nivel del individuo en el psicoanálisis y a nivel de la sociedad en el medio digital. Tu indicabas al comienzo la ambivalencia del medio digital que paga sus posibilidades de comunicación global al costo de un empobrecimiento de las numerosas dimensiones de la comunicación humana. Pero también podemos decir que la red digital ofrece nuevas posibilidades de interacción social casi inimaginables hace, digamos, unos cincuenta años. Estas posibilidades implican también una reinterpretación de los códigos que mencionaba recién. 
Creo que podemos resumir el tema que hemos tratado constatando la ambigüedad del secreto como dispositivo de exclusión. Por un lado vemos claramente que a nivel político hay muchas veces gran interés en no develar un pasado relacionado, por ejemplo, con heridas provocadas por regímenes dictatoriales. El secreto como dispositivo de represión en la memoria social tiene en este caso un carácter de censura y bloqueo de un proceso de recuperación de una identidad lesionada o de una herida abierta que no se quiere reconocer como tal. Pero por otro lado tenemos aspectos de la vida diaria que todos pensamos que deben ser protegidos y guardados en forma secreta dado que en caso contrario se produce una situación de peligro. La constitución alemana ("Grundgesetz") declara al secreto postal como un derecho fundamental y también lo hace la Declaración Universal de Derechos Humanos en el artículo 12.

Naturalmente que hay que ver a este derecho en conjunción, por ejemplo, con la libertad de prensa. Está claro también que la protección de la correspondencia privada establece una relación de secreto frente a la inferencia del estado que no es igual, por ejemplo, a la del intento del estado de mantener secretos recuerdos sociales que puedan poner en peligro a poderes vigentes. Hay aquí una relación entre secreto y tiempo que sería importante profundizar en el marco de una antropología cultural y filosófica.

Lo que caracteriza a la problemática del secreto en la sociedad de la información digital es un cambio topológico del secreto como algo relacionado al individuo humano en su concreción corporal y psíquica, a algo relacionado con la exterioridad de su intimidad individual y/o social en aparatos de memoria digital como son el laptop y el celular. Los debates actuales sobre las posibles formas de observación e intrusión estatal secreta con la fundamentación de la seguridad pública frente a la amenaza del terrorismo son un indicio claro de este cambio topológico. En otras palabras, cuando hablamos de secreto y memoria en el contexto actual de la sociedad de la información digital abarcando desde los secretos individuales, pasando por los secretos empresariales hasta los secretos de estado, nos estamos refiriendo sobre todo a los aparatos digitales en los cuales dichos secretos están almacenados siendo protegidos por leyes fundamentales y específicas.

El debate que se abre es entonces el de determinar cuáles son los límites éticos y legales de dicha protección en circunstancias concretas, es decir, de determinar cuándo se pasa a borrar la diferencia entre lo secreto y lo público de tal manera que el espejismo de una sociedad abierta que no admita ningún tipo de protección a la privacidad - el creer que todos pueden decir todo a todos y que todos pueden tener acceso a todo sin ningún tipo de respeto a, por ejemplo, los derechos de propiedad intelectual - no es sino el reverso de una sociedad fascista en la que sólo un grupo de personas se adjudica el derecho a hurgar en la memoria corporal y/o digital de los ciudadanos sin marco legal que los proteja tanto de la arbitrariedad estatal como del espionaje e intromisión sin su consentimiento. Pienso que la solución a este problema de la diferencia entre lo público y lo secreto (incluyendo lo privado) no ha de buscarse en un intento de creer que se pueda fijar definitivamente una línea de demarcación sino en mantener abierta la discusión política y académica que observe las razones por la cuales en determinadas situaciones sea conveniente mover la demarcación en uno u otro sentido. Lo básico en una sociedad democrática es que dicho debate sea público.

Raquel En estas contradicciones del mundo actual que justamente tu señalas no siempre es fácil navegar. Quiero evocar al respecto la figura de Alan Turing (1912-1954) que puede ser considerado uno de los padres de la Inteligencia Artificial y cuya vida se trama dramáticamente con el tema que nos convoca. Durante la segunda guerra mundial Turing formó parte del equipo de inteligencia que diseñó en Inglaterra una máquina llamada la 'Bomba' con la finalidad de explorar las combinaciones posibles generadas por la máquina codificadora alemana 'Enigma'.

Trabajó después en la Universidad de Manchester y en el programa MADAM (Manchester Automatic Digital Machine) que resultó ser el equipo de computación de mayor memoria construido hasta entonces. Pero su trabajo de descifrador de enigmas se acompañó después de la guerra de un descuido que le fue fatal. Turing denunció en la policía local un robo del que fue víctima, efectuado por un partenaire casual con el que había compartido la noche. Creyó que su homosexualidad podía ser pública y no midió las consecuencias sociales de sus declaraciones. Fue condenado a causa de su homosexualidad a un tratamiento o tortura, médico-farmacéutica equivalente a la castración. Turing se suicidó en 1954, 
comiendo una manzana envenenada. Se dice que la manzana de Apple lo recuerda con un guiño. Esto para acentuar que el juego de las contradicciones en las que vivimos es un juego que a veces se torna peligroso y no puede ser jugado de modo ingenuo. El otro punto con el que quiero terminar para abrir a un diálogo más amplio es el de subrayar que estar aquí reunidos para debatir sobre estos temas, marca como acontecimiento el límite de los espacios virtuales y el irremplazable lugar de encuentro de los cuerpo vivos que se regocijan en el hablar y el escucharse unos a otros.

Rafael Y también son claros los límites de los encuentros corporales sobre todo viendo las posibilidades del intercambio de información digital como lo hemos venido haciendo en este diálogo transatlántico. Creo que el ensamblaje entre los mensajes digitales y el encuentro faz a faz es algo que caracteriza a las sociedades de la información en este siglo. Es justamente este ensamblaje el que crea nuevos desafíos éticos con respecto a la delimitación entre informaciones públicas e informaciones secretas sobre todo si recordamos que el adjetivo 'secreto' no es algo inherente a una información sino una adjudicación a una relación siendo 'información' a su vez una categoría de segundo orden es decir dependiente del sujeto o sistema que la percibe como tal. Las diversas paradojas de la sociedad de la información a las que nos hemos referido podrían sintetizarse con el término de paradoja de Google: la buscadora quiere hacer accesible a todos, ella sola, toda la información digital manteniendo secreto su algoritmo.

\section{Agradecimiento}

Los autores agradecen al Prof. Oscar Krütli (Provincia de Córdoba, Argentina) por su crítica a este texto.

\section{Bibliografía}

Allouch, Jean: Le sexe de la vérité. Paris: Cahiers de l'unebévue, Epel 1998.

Boneberg, Hemma: Geheimhaltung. En: Christoph Auffarth, Jutta Bernard, Hubert Mohr Ed.: Metzler Lexikon Religion. Stuttgart: Metzler 1999, Vol. 1, p. 460-462.

Capurro, Rafael: Ethik der Informationsgesellschaft. Ein interkultureller Versuch. 2006. Online: http://www.capurro.de/parrhesia.htm/

Foucault, Michel: Discourse and Truth: the Problematization of Parrhesia, 1983 Online: http://foucault.info/documents/parrhesia

Geffroy, Lucie: Blogs d'écrivains, au-delà de l'intime. En: Magazine littéraire, No. 11, Mars-Avril 2007, p. 27. Derrida, Jacques: Mal d'archive, Paris: Galilée 1995.

Freud, Sigmund: Das Unbehagen in der Kultur. En ibid.: Fragen der Gesellschaft. Ursprünge der Religion. Frankfurt am Main: S. Fischer 1974, p. 191-270.

Freud, Sigmund y Fliess, Wilhelm: Briefe an Wilhelm Fliess. Frankfurt am Main, S. Fischer 1986.

Jullien, François: Le détour et l'accès. Stratégies du sens en Chine, en Grèce. Paris: Seuil 1995.

Jullien, François: Nourrir sa vie. À l'écart du bonheur. Paris, Seuil 2005.

Lacan, Jacques: Ecrits. Paris: Seuil, 1966.

Lacan, Jacques: Le Séminaire, VII, L'éthique de la psychanalyse. Paris: Seuil, 1986/1960, cap. XI.

Lacan, Jacques: Le Seminaire: D'un Autre à l'autre. Paris: Seuil 2006.

Lacan, Jacques: L'Unebévue, En: Revue de psychanalyse 2004, no21. Paris: Epel.

Simmel, Georg: Das Geheimnis und die geheime Gesellschaft. En: ibid.: Soziologie. Untersuchungen über die

Formen der Vergesellschaftung. Frankfurt am Main, 1995. p. 383-455. http://socio.ch/sim/unt5a.htm

Strauss, Leo: La persécution et l'art d'écrire. Paris, Presses Pocket 1989 (orig. 1952).

Wittgenstein, Ludwig: Tractatus logico-philosophicus. Frankfurt am Main: Suhrkamp 1984. 